\title{
Analysis of Guanzhong Traditional Residence Spatial Form and Surroundings
}

\author{
Jing. Liu* \\ 15234009646 \\ 493003140@qq.com*
}

No. 5 of FuDong Street of Xinghualing District, Taiyuan city, Shanxi province ,China

Keywords: Guanzhong Traditional Residence; Grand House; Narrow Courtyard; Sealing; Spatial Form

Abstract. Guanzhong traditional residence is involved in the traditional residence of North China, whose space layout is still traditional courtyard layout of China. Due to the impact of geographic position, culture, religion, life style and customs, traditional residence in Guanzhong is equipped with the space status of "grand house, narrow courtyard and sealing". Meanwhile, in order to adapt to the climate that it is sultry in summer and to the dust invasion, the mansions of both sides rise highly towards the single slope inside, and the courtyard becomes a fine shadow region in summer. It can not only meet the requirement in residents' daily life but also can help to prevent from the invasion of wind sand, and finally the value characteristics of old town are generalized and summarized.

\section{OVERVIEW ON THE NATURAL CONDITION AND HISTORICAL CULTURE IN GUANZHONG}

Guanzhong is what Shaanxi natives called Weihe Plain, located in the middle zone of Shaanxi, North-east China. It stretches from "Hangu Pass" of Ling-bao in the east to "San-kuan Pass" in the west, in-cluding Xi'an, Baoji, Xianyang and other large and medium-sized cities. Qian Mountain is in its north, vast plain in the middle, and the terrain tilts from northwest to southeast. Mountains, rivers, tableland are all involved in the region, and Weihe River and Weishui River pass through this area, which forms the geomorphic characteristics that "one river be-tween two mountains, two rivers separates three tab-leland". The whole area of Guanzhong is affected by the sub-humid warm temperate continental monsoon climate. Guanzhong Plain of Shaanxi is one of the birthplaces of Chinese ancient culture, where rich culture of Qin had been bred. There is still large pa-lace relic in the early period of Western Zhou within Guanzhong - Fengchu Site, the originator of Chi-nese construction in courtyard style. Guanzhong res-idence with long history still reserves a wide variety of residences in Ming and Qing Dynasty, among which, residences in Xi'an, Sanyuan and Hancheng are most representative.

Guanzhong traditional residence is involved in the traditional residence of North China, whose space layout is still traditional courtyard layout of China. Due to the impact of geographic position, culture, re-ligion, life style and customs, as well as the various geographic positions of traditional residence in dif-ferent areas of China, it displays diverse forms and characteristics [1].

For cold in winter and hot in summer, along with summer drought, it is the relatively sultry area in the northern climatic zone. In summer, with strong sun-shine and low rainfall, sun protection becomes the principal requirement for residential architecture. There is no window on the outer wall of building, mainly towards the courtyard to gather light, so nearly half of the buildings are always in shadow all the year round. All these different spatial forms are aimed to fit the climate and geographical conditions, to improve the micro-climate in the yard and save land. It forms the characteristics of traditional resi-dence in Guanzhong - "grand house, narrow cour-tyard and sealing". The space of whole narrow cour-tyard is more closed and compact, with powerful centripetal force, which displays the substantial de-fensive. 


\section{PLANE LAYOUT OF TRADITIONAL RESIDENCE IN GUANZHONG}

The plane layout of residence in Guanzhong is simi-lar to that of the traditional courtyard, but equipped with its own local style and features at the same time. House with a courtyard is the most basic layout form of traditional residences in Guanhzong. This kind of layout form usually arranges the rooms along with the surrounding of land, from the front to back, followed by gate house, courtyard, principal room and backyard. In order to gain more available space, two houses with single pitch roof are placed in the two sides of courtyard to form the quadrangle dwel-lings. The ground-support width of this type is about 8 to 10 meters, and the depth is about 20 meters. For it is narrow and long, the land can be used adequate-ly and less occupied.

Mostly depending on the open size in the middle of the principal room, the width of traditional courtyard in Guanzhong is approximately 3 meters; the depth of courtyard is affected by the number of wing-rooms of two sides, and the ratio of length and width of courtyard is $3: 1$ or $4: 1$, which finally constitutes the narrow and long courtyard. The open space of gate house and principal room is about 3 meters and some is built with larger space. The plane arrangement is tide. The plane layout with courtyard can not only be used separately, but also can be applied to form a variety of flats with lots of courtyards in the longitudinal direction or connected courtyards in the horizontal direction. Therefore, this type of layout with courtyard is the fundamental component unit of traditional residences in Guan-zhong area.

The patter of layout planning which is repeatedly constituted by the residences with courtyard in the longitudinal direction is relatively common in the ci-ties and towns of Guanzhong. For the limited land resource and large population, the homestead is di-vided into three open rooms with width of 10 meters, and consequently it is equipped with narrow facade and large depth. Upon this plane layout, the function of all halls and courtyards is comparatively distinct, concise and adaptable. The requirements of residents towards privacy and quietness are met because of flexible space and decreased density of road network, and the largest merit of this kind of courtyard is optimal land utilization. If one rich family buys two houses with multiple courtyards of both sides, several houses with multiple courtyards in the plane is formed and connected by a number of "walls and doors" in the horizontal direction, which forms the space layout with one courtyard laterally. Each courtyard has independently external gateway so that the whole family can get along well with each other without interruption.

\section{SPACE CHARACTERISTICS OF TRADITIONAL RESIDENCE IN GUANZHONG}

For the space layout of residence in Guanzhong is in the form of long, narrow, rigorous and neat, the pro-portion of courtyard is narrow and long. Usually, the courtyard is surrounded by the wall, door, reverse sit, mansion and hall and separated by the hall, principal room, wall and doorway. It adjusts the pro-portion of courtyard and enriches the spatial levels.

\section{Elements of Space Enclosure}

Gate of yard is the architectural element with the most ornamental value. The gate of traditional resi-dence in Guanzhong embodies the fine tile carving and exquisite workmanship. Generally, the door is in the southeast corner, with plaque on it. When open the door, mountains will come into sight and the house is built with the screen wall. Some Taihu stones are placed in the front of screen wall, sur-rounded by the trees and flowers. It can not only de-corate the house, but also provide a wind barrier and keep the outer sight out, which can increase the pri-vacy; meanwhile, screen wall inside the door is also regarded as a means to show the house style, where carved with colorful pictures with eager for peace. Except for the aspect of spirit, it also adds the space meaning and visual sense. 


\section{Gate of Yard}

Gate of yard is the architectural element with the most orna-mental value. The gate of traditional residence in Gua-nzhong embodies the fine tile carving and exquisite work-manship. Generally, the door is in the southeast corner, with plaque on it. When open the door, mountains will come into sight and the house is built with the screen wall. Some Taihu stones are placed in the front of screen wall, surrounded by the trees and flowers. It can not only decorate the house, but also provide a wind barrier and keep the outer sight out, which can increase the privacy; meanwhile, screen wall inside the door is also regarded as a means to show the house style, where carved with colorful pictures with eager for peace. Except for the aspect of spirit, it also adds the space meaning and visual sense.

\section{Reverse Sit}

For the residence in Guanzhong usually faces south, reverse sit is the headmost house of courtyard, opposite to the principal room, as the beginning of spatial series. There are 3 to 5 reverse sits in one courtyard, where servants live in. Sometimes, it can also be used for other purposes.

\section{Mansion}

Mansion had played a very important role in the enclosure and division of courtyard of traditional residence in Gua-nzhong, and the overall length of mansion controls the size of each courtyard. Under the circumstance that the overall depth of house site is unchanged, the length of mansion of each courtyard is relatively flexible. The interval of traditional buildings is odd, increasing and decreasing in order by 3,5, 7 and 9, which had been the custom. The wing-room in the courtyard is no exception. However, the interval of mansion in Guanzhong region had not strictly followed this convention, for 1 , 2 and 3 still exist. In this way, the depth of courtyard can be divided flexibly in accordance with the real condition to produce different courtyards. Commonly, the structure size of open space of mansion is about 2.4 meter, less than that of other houses. The depth is no more than 3 meters because of the slope structure. The mansion is relatively soaring so that it constitutes a fine shadow area for courtyard in summer, which can satisfy the demand of residence in daily life; meanwhile, it can protect the house from the sandstorm attack. The mansions are independent, not connected with each other.

\section{Hall and Principal Room}

A majority of residences in Guanzhong are equipped with hard-mountain sloping roof, and the requirement of integral shape of principal room is particularly outstanding. One layer of attic is added on the principal house of many old residences, only for reserving the articles and for decorating. It is mainly aimed at increasing the level of scattered wave for the external image of courtyard. The hall can be opened from the front and back, so people can pass through the hall to the backyard in the middle. A wealthy and influential family in the past usually has a forecourt to carry out the production activities and a part of daily social activities. About the building materials, quality and decoration, the hall and principal room are better than other architectures.

\section{Spatial Strategy \\ Distinct Space with courtyard}

In people's mind, courtyard is deemed as the basic composition unit of traditional Chinese architecture [2]. The pattern and spatial size of courtyard in Guanzhong are determined by the external cause of limited land and large population. Therefore, the narrow and long courtyard with quadrangle dwellings is shaped naturally because of the integration of land and external space between houses. The advantage of this kind of narrow courtyard is that is not only save the land but also solve the problems like sunshade, avoiding summer heat, dust proof, ventilation and outdoor drainage.

\section{Courtyard Greenery}

Greenery has substantial impact on enriching the courtyard space, beautifying the environment and adjusting the microclimate. Because the courtyard of residence in Guanzhong region is narrow, with 
small area, it is unable to realize the large greenery like that of regions south of the Yangtze River. Usually, some flowers and trees will be planted inside the small courtyard, such as wintersweet, magnolia denudate, pomegranate, oleander and other dungarunga. Some will arrange the flowers, plants and bonsai on the still and handrail or under the eave; some will develop a small piece of green land in the corner of courtyard for householder to plant. All these means creates a comfortable and quiet living atmosphere for the courtyard.

\section{Space Penetration}

The plane layout of residence in Guanzhong is narrow, long, ri-gorous and neat, but the changes of combination of house and courtyard can enrich the relation of internal space and meet the requirement in daily life, and even create different temperament and interest and colorful living environment. For hall, passage and courtyard are connected with each other, it offers the possibility to mutual extend internally and externally, and also develops a space effect with hie-rarchy and permeability, and consequently makes the space of courtyard become more comfortable.

\section{CHARACTERISTICS OF TRADITIONAL RESIDENCES IN GUANZHONG}

\section{Safety, intimacy}

In the modern architecture theory, enclosure is the most concise and effective method in terms of space limit, while the height and width and people's thought give a critical role for the enclosed house. Courtyard of traditional residence in Guanzhong is enclosed with reserve sit, hall and mansion, and the height and width of courtyard in the horizontal direction is $1: 1$, while 1:4 in the longitudinal; mean-while, the mansion, hall and wall have no windows and people can feel safe for it is difficult to be climbed. The internal opening can enhance the mutual exchange among family members and people can fell friendly within this environment.

\section{Ecology}

Traditional courtyard is close to the Nature for it is opened to the outside world. Daily life is carried out around the courtyard, several steps from interior to exterior. In summer, it is hot inside the house, so the resident can go to courtyard to enjoy the cool; in winter, the resident can enjoy the sunshine in the courtyard for the house inside is gloomy and cold. At the meantime, courtyard still takes the substantial functions - living, eating, playing and even reading, and every character can be played. People living the courtyard can freely enjoy the fresh to have a breath of fresh air and feel the changes of weather in differ-ent seasons and to touch the pulse of Nature.

\section{CONCLUSION}

By analysis on the morphological characteristics and space characteristics of traditional residences from the angles like method of plane layout, spatial organ-ization and features, we can draw a conclusion that all of the specific physiographic condition, long his-torical culture commonly creates the vigorous, plain space status. The existing spiritual culture value con-tained in the excellent traditional residence in Gua-nzhong is far more than its original use value. It re-flects and reappears the current culture and living condition from one side, to provide the spiritual yearnings to the past life and to add a mode which can be learnt for the modern living pattern.

\section{REFERENCE:}

[1] Jing Qimei, Zhang Li'an. Traditional Chinese Residence [M]. Beijing: China Electric Power Press, 2007: 1-12. 
International Forum on Energy, Environment Science and Materials (IFEESM 2015)

[2] Li Yunsu, CATHAY'S IDEA [M]. Tianjin: Tianjin University Press, 2005: 127-158. 